\title{
Kinetic Studies on Transesterification of Biodiesel Prepared in Ionic Liquids
}

\author{
Yang Bo \\ Department of Chemistry and Environment Engineering, \\ JiuJiang University, \\ JiuJiang 332005, China \\ To Whom correspondence should be addressed. \\ e-mail:boyang2618@163.com
}

\begin{abstract}
When the mole ratio of catalyst quantity to reactants was 0.019 , that of alcohol to oil was 12 , the reaction temperature was $150^{\circ} \mathrm{C}$, the kinetics of transesterification of triolein with methanol was studied by means of four kinds of ionic liquids with netrogen chemical groups and different anions as catalysts. Through experiments of kinetics and by Matlab programs and regression of the experimental data, the reaction dynamics rate equation were determined. What's more, the catalytic activities of ionic liquids were investigated. The results showed the model calculation results were in very good agreement with experimental data, and that the catalytic activities were associated with the structures of nitrogen chemical groups, anionic acid strength and acid volume.
\end{abstract}

Keywords-ionic liquids; biodiesel; transesterification;

\section{INTRODUCTION}

In recent years, with the exhaustion of petroleum resource and the increase of petroleum price, the world is facing a crisis of energy shortage. At the same time, with the deterioration of ecological environment and the enhancement of environmental awareness, people begin to realize the severity of the air pollution caused by petroleum. Biodiesel is an environmental friendly, clean and renewable new green energy resource. It is a substitute for petroleum diesel oil, which is produced by chemical reaction from cottonseed oil, peanut oil, rapeseed oil, gutter oil, industrial lard, beef tallow and waste cooking oil. It not only has a combustion performance as good as traditional petroleum diesel oil, but also has better properties than mineral fuels, such as biodegradability, high flash point, nontoxicity, environmental friendliness, reproducibility, high unit heat, sulphur-free and aromatic compound-free. Therefore, the study and application of biodiesel has attracted extensive attention in the world and become a hotspot in the development of new energy resources ${ }^{[1-2]}$.

As a green solvent and catalyst ${ }^{[3-4]}$, ionic liquid has attracted extensive attention at home and abroad due to its advantages ${ }^{[5-6]}$. At present, preparation of biodiesel under the catalytic action of ionic liquid has been reported in many literatures. However, these literatures put emphasis on developing a new acidic catalyst using the structure adjustability of ionic liquid and investigating its catalytic activity under different reaction conditions and pay little attention to the study of the dynamic behavior of transesterification, especially the comparative study of the dynamic behavior of the preparation of biodiesel by transesterification under the action of different types of acidic ionic liquid catalysts. The author has designed and synthesized four types of nine protonated acidic ionic liquids for preparation of biodiesel, used these as the catalysts to study the transesterification reaction between the simulated raw oil glycerol trioleate and methyl ester, discussed the homogeneous reaction kinetics of the transesterification reactions catalyzed by different types of ionic liquids based on experimental data and evaluated the catalytic activities of different catalysts.

\section{EXPERIMENTS}

\section{A. Instruments and Reagents}

Shimadzu 10A liquid chromatograph, manufactured by Japan Shimadzu Company; WDF-0.5 magnetic stirring high pressure reactor, manufactured by China Shandong Weihai Automatic Reactor Company; R301 rotation evaporator, manufactured by China Shanghai Shenshun Bio-Tech Co., Ltd.; 2XZ-2 $0.37 \mathrm{kw}$ rotary vacuum pump, manufactured by China Shanghai Vacuum Pump Factory.

Acetone and acetonitrile, chromatographically pure; pyridine, 2-methylpyridine, triethylamine, concentrated $\mathrm{H}_{2} \mathrm{SO}_{4}$, concentrated $\mathrm{H}_{3} \mathrm{PO}_{4}$, concentrated $\mathrm{HNO}_{3}$, anhydrous ether, ethyl acetate, anhydrous methanol, anhydrous ethanol, analytically pure; glycerol trioleate, chemically pure; glyceryl dioleate and glyceryl monooleate, with a purity of $\geq 99 \%$; N-methylimidazole, with a purity of $\geq 98 \%$.

\section{B. Preparation and Characterization of Ionic Liquids}

Four types of nine protonated ionic liquids having different nitrogen-containing functional groups are prepared, which are expressed as 1\#-9\#. Their structures are shown in Figure 1. Their structures and physical properties are characterized by NMR, FT-IR, ESI-MS, TG/DTA characterization methods. The purity of the ionic liquid prepared is greater than $95 \%$ and the synthesis and purification methods of the ionic liquids are reliable and can prepare high purity ionic liquids. 
<smiles>CC[NH+]([125I])CC</smiles>
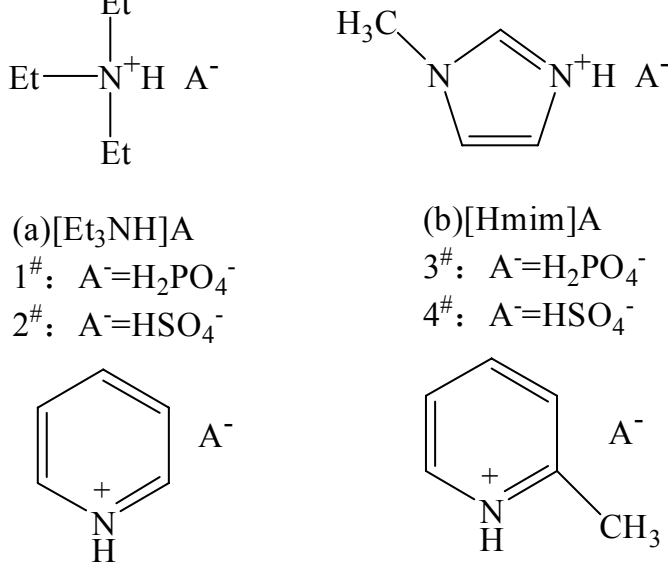

(b) $[\mathrm{Hmim}] \mathrm{A}$

$3^{\#}: \mathrm{A}^{-}=\mathrm{H}_{2} \mathrm{PO}_{4}^{-}$

$4^{\#}: \mathrm{A}^{-}=\mathrm{HSO}_{4}^{-}$<smiles>Cc1cccc[nH+]1</smiles>

(c) $[\mathrm{Py}] \mathrm{A}$

(d) $[\mathrm{MPy}] \mathrm{A}$

$5^{\#}: \mathrm{A}^{-}=\mathrm{H}_{2} \mathrm{PO}_{4}^{-}$

$7^{\#}: \mathrm{A}^{-}=\mathrm{H}_{2} \mathrm{PO}_{4}^{-}$

$6^{\#}: \mathrm{A}^{-}=\mathrm{HSO}_{4}^{-}$

$8^{\#}: \mathrm{A}^{-}=\mathrm{HSO}_{4}^{-}$
$9^{\#}: \mathrm{A}^{-}=\mathrm{NO}_{3}^{-}$

Figure 1. Structures of ionic liquids

\section{Transesterification Reaction Process}

During the experiment, first add glycerol trioleate and some of the methanol, heat up to the set temperature and then feed the remaining methanol with catalyst from the feed tank into the reactor via the liquid outlet of the high pressure reactor. In this way, the vapor-liquid equilibrium of methanol in the reactor can be maintained and the temperature will not drop dramatically. Measure the reaction temperature with the thermocouple connected to the main controller and adjust the heating voltage accordingly to control the heating rate. The temperature fluctuation range of the reactor is $\pm 5^{\circ} \mathrm{C}$. At the same time, the main controller controls the rotation speed of the stirring paddle to mix the reaction mass uniformly. During the reaction, the liquid is discharged and sampled via the valve at the liquid outlet of the high pressure reactor. To further purify the crude product, the methyl oleate can be separated from the product phase by vacuum distillation. Carry out vacuum distillation in the rotation evaporator at a vacuum degree of $2.00 \sim 2.67 \mathrm{kPa}$ and a distillation temperature of $180 \sim 230^{\circ} \mathrm{C}$. A light yellow transparent methyl oleate product is obtained by distillation.

\section{Product Analysis}

Product analysis is fulfilled by using Shimadzu 10A liquid chromatograph. The analysis conditions are: ODS-2 C18 silicane packed column, the mobile phase is acetone and acetonitrile $(1: 1)$, the ultraviolet analysis wavelength is $210 \mathrm{~nm}$, the column temperature is $40^{\circ} \mathrm{C}$. Since the components of the raw material are very simple, during the analysis, external standard quantitative analysis is carried out for the glycerol trioleate, glyceryl dioleate, glyceryl monooleate and methyl oleate. During the experiment, dry the sample in the air dry oven for 20 minutes at $110^{\circ} \mathrm{C}$ to remove the methanol. After removing the methanol, dissolve the sample in acetone to prepare a liquid of certain concentration. Then, put the liquid into an analysis flask, carry out sample injection and analysis automatically by a preset liquid chromatographic program, and compare with the standard curve respectively to solve for the mass fraction of each component in the sample.

\section{E. Technological Conditions}

The optimum technological conditions for the reaction kinetics of transesterification determined by orthogonal experiment are as follows: the molar ratio of methanol to oil is 12 , the reaction temperature is $170^{\circ} \mathrm{C}$, the amount of catalyst is $5.7 \%$ of the mole number of the reactant ${ }^{[7]}$.

\section{RESULTS AND DISCUSSION}

\section{A. Establishment of Kinetic Model}

The transesterification reaction between methanol and glycerol trioleate consists of three consecutive reversible reactions:

$$
\begin{gathered}
\mathrm{TG}+\mathrm{CH}_{3} \mathrm{OH} \underset{k_{-1}}{\stackrel{k_{1}}{\Leftrightarrow}} \mathrm{DG}+\mathrm{ME} \\
\mathrm{DG}+\mathrm{CH}_{3} \mathrm{OH} \underset{\mathrm{k}_{-2}}{\stackrel{k_{2}}{\Leftrightarrow}} \mathrm{MG}+\mathrm{ME} \\
\mathrm{MG}+\mathrm{CH}_{3} \mathrm{OH} \underset{k_{-3}}{\stackrel{k_{3}}{\Leftrightarrow}} \mathrm{GL}+M E
\end{gathered}
$$

In this formula, $\mathrm{TG}, \mathrm{DG}, \mathrm{MG}$ and $\mathrm{GL}$ respectively represent glycerol trioleate, glyceryl dioleate, glyceryl monooleate and glycerol. ME represents methyl oleate, $\mathrm{M}$ is used to represent the reactive material methanol.

Based on the knowledge of the transesterification reaction of glycerol trioleate, before establishing the kinetic model, we assume that:

(a) The influence of the impurities in the glycerol trioleate is ignored, i.e., we consider that only the transesterification reaction of TG exists;

(b) The catalyst concentration remains unchanged during the reaction, therefore the forward and reverse reaction rates observe the law of mass action, i.e., it is in direct proportion to the reactant concentration.

According the reaction mechanism given in Formula (1-3) and the above two assumptions, the dynamic differential equation of each component during the transesterification reaction of TG can be obtained:

$$
\left\{\begin{array}{l}
\frac{d[T G]}{d t}=-k_{1}[T G][M]+k_{-1}[D G][M E] \\
\frac{d[D G]}{d t}=k_{1}[T G][M]-k_{-1}[D G][M E]-k_{2}[D G][M]+k_{-2}[M G][M E] \\
\frac{d[M G]}{d t}=k_{2}[D G][M]-k_{-2}[M G][M E]-k_{3}[M G][M]+k_{-3}[G L][M E] \\
\frac{d[M E]}{d t}=k_{1}[T G][M]-k_{-1}[D G][M E]+k_{2}[D G][M]-k_{-2}[M G][M E]+k_{3}[M G][M]-k_{-3}[G L][M E]
\end{array}\right.
$$

The constraint condition equation between the concentrations of the various components can be obtained using the equilibrium relationship between the reaction product, the reactive material and the intermediate product:

$$
\begin{aligned}
& {[M]=[M]_{0}-[M E]} \\
& {[G L]=[T G]_{0}-[T G]-[D G]-[M G]}
\end{aligned}
$$


The initial conditions of the system of differential equations are:

$$
t=0:[T G]=[T G]_{0},[D G]=0,[M G]=0,[G L]=0
$$

\section{B. Determination of the Parameters of the Kinetic Model of Transesterification Reaction}

Solve the system of differential equations ${ }^{[8]}$ (4) by fourth-order Runge-Kutta method, write a program using Matlab $^{[14]}$, use nine groups of experimental data to compare the calculated concentrations with the experimental values, sum up the relative deviations between the experimental values and the calculated values and solve for the average relative error $\mathrm{S}$, i.e.,:

$$
S=\sum_{i=1}^{9} \sum_{0}^{t}\left(\left|y_{i}(t)_{\exp }-y_{i}(t)_{c a l}\right| / y_{i}(t)_{\exp }\right) / N
$$

In this formula, $\mathrm{y}_{\mathrm{i}}(\mathrm{t})$ is the concentration of methyl oleate at time $\mathrm{t}$ in the catalyst system of ionic liquid $\mathrm{i}, \mathrm{N}$ is the total number of the concentration values of methyl oleate measured in the catalyst systems of various types of ionic liquids during the experiment. Take minimizing the average relative deviation $\mathrm{S}$ in Formula (8) as the optimization goal and find out the forward and reverse reaction rate constants of each group.

1) Determination of Rate Constant

The reaction rate constants of the transesterification reactions catalyzed by different types of ionic liquids obtained by analog calculation are given in Table I. From this table, we can see that in the catalyst systems of the three ionic liquids $\left[\mathrm{Et}_{3} \mathrm{NH}\right] \mathrm{HSO}_{4}, \quad[\mathrm{HMIm}] \mathrm{HSO}_{4}$ and [MPy] $\mathrm{NO}_{3}$, the forward reaction rate constants $\mathrm{k}_{1}, \mathrm{k}_{2}$ and $\mathrm{k}_{3}$ of the three consecutive reactions are far less than the catalyst systems of the other types of ionic liquids and that the reverse reaction rate constants of the three consecutive reactions are significantly greater than the forward reaction rate constants. This has limited the conversion from triglyceride to methyl ester.

\begin{tabular}{|c|c|c|c|c|c|c|c|}
\hline \multirow{2}{*}{ Types of ionic liquids } & \multicolumn{7}{|c|}{ Rate constant $/ \mathrm{L} \cdot \mathrm{mol}-1 \cdot \min -1$} \\
\hline & $k_{1}$ & $\mathrm{k}_{-1}$ & $k_{2}$ & $k_{-2}$ & $k_{3}$ & $k_{-3}$ & $\mathrm{~S}$ \\
\hline$\left[\mathrm{Et}_{3} \mathrm{NH}\right] \mathrm{H}_{2} \mathrm{PO}_{4}$ & 0.0022 & 0.0101 & 0.0024 & 0.0026 & 0.0119 & 0.0082 & 0.1123 \\
\hline$\left[\mathrm{Et}_{3} \mathrm{NH}\right] \mathrm{HSO}_{4}$ & 0.0009 & 0.0467 & 0.0009 & 0.0262 & 0.0012 & 0.0033 & 0.1815 \\
\hline$[\mathrm{HMIm}] \mathrm{H}_{2} \mathrm{PO}_{4}$ & 0.0021 & 0.0066 & 0.0026 & 0.0022 & 0.0016 & 0.0003 & 0.1031 \\
\hline$[\mathrm{HMIm}] \mathrm{HSO}_{4}$ & 0.0004 & 0.0062 & 0.0007 & 0.0021 & 0.0020 & 0.0049 & 0.2802 \\
\hline$[\mathrm{Py}] \mathrm{H}_{2} \mathrm{PO}_{4}$ & 0.0046 & 0.0137 & 0.0051 & 0.0037 & 0.0014 & 0.0001 & 0.1279 \\
\hline$[\mathrm{Py}] \mathrm{HSO}_{4}$ & 0.0036 & 0.0415 & 0.0306 & 0.0460 & 0.0024 & 0.0029 & 0.1038 \\
\hline$[\mathrm{MPy}] \mathrm{H}_{2} \mathrm{PO}_{4}$ & 0.0029 & 0.0053 & 0.0049 & 0.0041 & 0.0021 & 0.0002 & 0.1281 \\
\hline$[\mathrm{MPy}] \mathrm{HSO}_{4}$ & 0.0066 & 0.0686 & 0.0342 & 0.0344 & 0.0022 & 0.0019 & 0.0660 \\
\hline$[\mathrm{MPy}] \mathrm{NO}_{3}$ & 0.0013 & 0.1406 & 0.0014 & 0.0538 & 0.0001 & 0.0173 & 0.1322 \\
\hline Py-mixture & 0.0036 & 0.0073 & 0.2002 & 0.7254 & 0.0040 & 0.0014 & 0.1233 \\
\hline MPy-mixture & 0.0091 & 0.0621 & 0.0043 & 0.0026 & 0.0051 & 0.0027 & 0.2223 \\
\hline
\end{tabular}

TABLE I. VALUES OF RATE CONSTANTS $\mathrm{K}_{1}-\mathrm{K}_{-3}$ AND AVERAGE DIFFERENCE S

Note:Py-mixture represent $[\mathrm{Py}] \mathrm{HSO}_{4} \&\left[\mathrm{Py}_{\mathrm{H}} \mathrm{PO}_{4}, \quad \mathrm{MPy}\right.$-mixture represent $[\mathrm{MPy}] \mathrm{HSO}_{4} \&\left[\mathrm{MPy}_{2} \mathrm{H}_{2} \mathrm{PO}_{4}\right.$

\section{2) Comparison between Calculation Results and} Experimental Data

Use the forward and reverse reaction rate constants (Table I) obtained by analog calculation and the system of dynamic differential equations (4) to calculate the variation of the concentrations of the various components in the reaction system with the reaction time at any temperature and any initial concentration and then calculate the conversion rate of the reactant and the product yield during the reaction. The comparison between the analog calculation values and experimental values of the $[\mathrm{Py}] \mathrm{HSO}_{4}$ and $[\mathrm{MPy}] \mathrm{HSO}_{4}$ catalytic reaction systems at $170{ }^{\circ} \mathrm{C}$ is given in Figure 2 and 3. In these figures, the analog calculation values are expressed in the form of curves and the experimental values are expressed in the form of coordinates. From these figures, we can see that the calculation results match well with the experimental data. As a result, the kinetic model established in this paper can well reflect the kinetic process of the transesterification reaction between glycerol trioleate and methanol catalyzed by ionic liquids. 


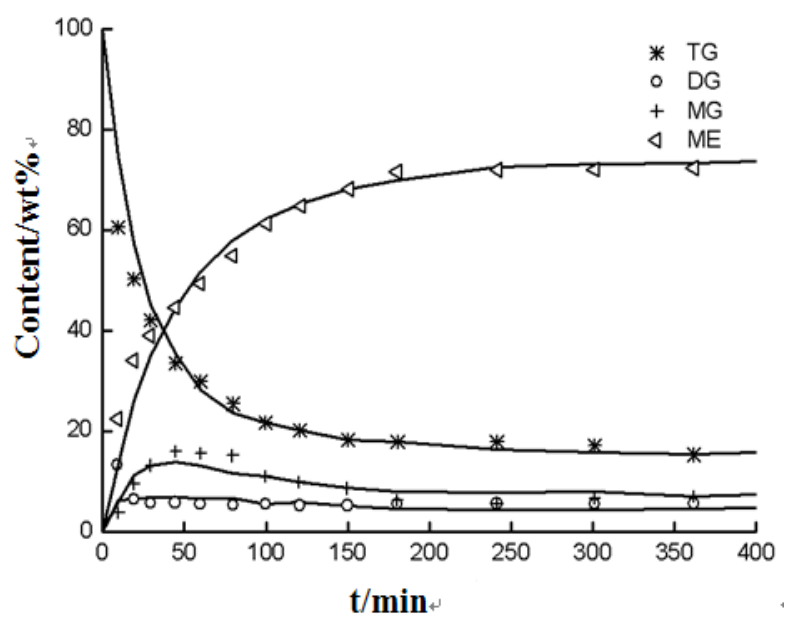

Figure 2. Comparisons of calculated and experimental concentrations under [Py]HSO4

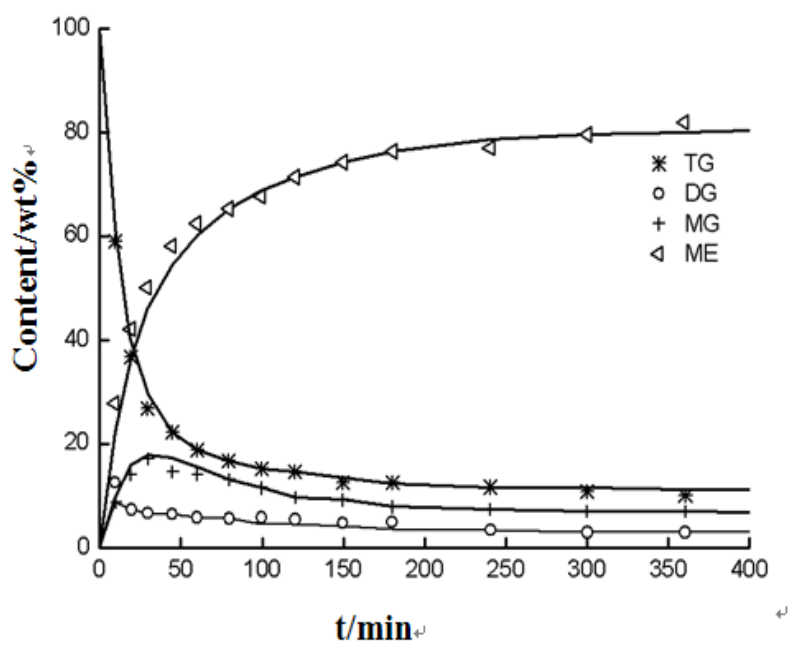

Figure 3. Comparisons of calculated and experimental concentrations under [MPy]HSO4

3) Comparison between the activities of ionic liquids

According to the analog result of reaction kinetics, the reaction rate, conversion rate and yield of methyl ester at any reaction time and the reaction time required at a specific conversion rate can be calculated. Therefore, according to the rate constant obtained by fitting, four data of the transesterification reactions catalyzed by nine ionic liquids and two groups of mixed ionic liquids are investigated, including the initial reaction rate (the generation rate of methyl ester at the reaction time of $5 \mathrm{~min}$ ), the reaction time required when the mass fraction of methyl ester reaches $50 \%$ and the mass fractions of methyl ester at the reaction time of $50 \mathrm{~min}$ and $6 \mathrm{~h}$, to compare the catalytic activities of the ionic liquids and further validate the results of the previous study. These four data almost cover all stages of the reaction and give a true description of the transesterification reaction process.

The four data under the catalytic action of nine ionic liquids and two groups of mixed ionic liquids are given in Table II. First, from this table, we can see that the order of the initial (5min) generation rates of methyl ester is: $8 \#>11 \#>10 \#>6 \#>7 \#>5 \#>1 \# \approx 3 \#>9 \#>4 \#>2 \#$. Except for $10 \#[\mathrm{Py}] \mathrm{HSO}_{4} \&[\mathrm{Py}] \mathrm{H}_{2} \mathrm{PO}_{4}$ whose result slightly differs from the actual reaction process curve, all of the others match well with the actual reaction of the catalyst system. For the same anion $\mathrm{H}_{2} \mathrm{PO}_{4}^{-}$or $\mathrm{HSO}_{4}^{-}$, the order of the catalytic activities of the cations is 2-methylpyridine $>$ pyridine $>$ methylimidazole $>$ quaternary ammonium. For the same cation, $\mathrm{HSO}_{4}{ }^{-}>\mathrm{H}_{2} \mathrm{PO}_{4}{ }^{-}$is basically satisfied. At the reaction time of $50 \mathrm{~min}$, the order of the mass fractions of methyl ester is: $>10 \#>11 \#>6 \#>7 \#>5 \#>1 \#>3 \#>4 \#>9 \#>2 \#$. This is in inverse proportion to the time used by the catalyst system when the mass fraction of methyl ester in the system reaches $50 \%$ and is basically consistent with the order of the initial reaction rates. At the reaction time of $6 \mathrm{~h}$, the order of the mass fractions of methyl ester in various catalyst systems

$7 \#>5 \#>11 \#>10 \#>3 \#>8 \#>1 \#>6 \#>4 \#>2 \#>9 \#$. This differs significantly from the orders of the above three indexes. The order numbers of the catalyst systems containing $\mathrm{H}_{2} \mathrm{PO}_{4}^{-}$have moved forward due to the catalystic characteristics of $\mathrm{H}_{2} \mathrm{PO}_{4}^{-}$. It is possible that in the first half of the reaction, the acid strength of the ionic liquid catalyst has a decisive effect on the reaction rate, the higher the acid strength, the higher the reaction rate; while in the second half of the reaction, if the catalyst has a high acid content, the reaction rate will be high. Finally, a higher mass fraction of methyl ester is obtained. The analysis of the four catalytic activity results of ionic liquids are consistent with the activity results of the transesterification reactions catalyzed by ionic liquids obtained in the experiments. 
TABLE II. CATALYTIC PERFORMANCE OF TRANSESTERIFICATION WITH DIFFERENT IONIC LIQUIDS

\begin{tabular}{|c|c|c|c|c|}
\hline $\begin{array}{l}\text { Types of ionic } \\
\text { liquids }\end{array}$ & $\begin{array}{l}5 \mathrm{~min} \text { reaction rate } \\
\mathrm{r} / \mathrm{mol}^{-\mathrm{L}^{-1}} \cdot \mathrm{min}^{-1}\end{array}$ & $\begin{array}{l}\text { The reaction of } 50 \text { min time } \mathrm{CME} \\
\text { /wt. } \%\end{array}$ & $\begin{array}{c}\mathrm{CME}=50 \% \text { reaction time } \\
\mathrm{t} / \mathrm{min}\end{array}$ & $\begin{array}{c}\text { The reaction of } 6 \text { hours } \mathrm{CME} \\
\text { /wt. } \%\end{array}$ \\
\hline$\left[\mathrm{Et}_{3} \mathrm{NH}\right] \mathrm{H}_{2} \mathrm{PO}_{4}$ & 0.0121 & 29.69 & 97.88 & 80.34 \\
\hline$\left[\mathrm{Et}_{3} \mathrm{NH}\right] \mathrm{HSO}_{4}$ & 0.0043 & 9.41 & More than 400 minutes & 28.26 \\
\hline$[\mathrm{HMIm}] \mathrm{H}_{2} \mathrm{PO}_{4}$ & 0.0117 & 26.70 & 113.21 & 82.17 \\
\hline$[\mathrm{HMIm}] \mathrm{HSO}_{4}$ & 0.0091 & 15.13 & More than 400 minutes & 33.42 \\
\hline$[\mathrm{Py}] \mathrm{H}_{2} \mathrm{PO}_{4}$ & 0.0245 & 43.76 & 63.10 & 90.78 \\
\hline$[\mathrm{Py}] \mathrm{HSO}_{4}$ & 0.0298 & 47.54 & 55.53 & 72.41 \\
\hline$[\mathrm{MPy}] \mathrm{H}_{2} \mathrm{PO}_{4}$ & 0.0165 & 37.42 & 73.77 & 91.58 \\
\hline$[\mathrm{MPy}] \mathrm{HSO}_{4}$ & 0.0484 & 57.07 & 35.30 & 81.97 \\
\hline$[\mathrm{MPy}] \mathrm{NO}_{3}$ & 0.0072 & 11.22 & More than 400 minutes & 20.89 \\
\hline Py-mixture & 0.0341 & 52.85 & 45.27 & 84.27 \\
\hline MPy-mixture & 0.0385 & 49.89 & 50.00 & 85.93 \\
\hline
\end{tabular}

Note:Py-mixture represent $10 \#[\mathrm{Py}] \mathrm{HSO}_{4} \&[\mathrm{Py}] \mathrm{H}_{2} \mathrm{PO}_{4}$

MPy-mixture represent $11 \#[\mathrm{MPy}] \mathrm{HSO}_{4} \&\left[\mathrm{MPy}^{2} \mathrm{H}_{2} \mathrm{PO}_{4}\right.$

\section{CONCLUSION}

Under the optimum technological conditions, the contents of the various components are determined with the high performance liquid chromatograph by external standard method. The kinetic model of the transesterification reaction between glycerol trioleate and methanol is established based on the experimental data and the forward and reverse rate constants of the three consecutive reactions in the transesterification reaction of ionic liquids are obtained on this basis. The result shows that, the analog calculation results of the transesterification reaction in ionic liquid catalysts match well with the experimental data. The cation of the ionic liquid has a decisive effect on the reaction rate. In the initial stage of the reaction, the acid strength of the ionic liquid plays an important role in the reaction; in the later stage of the reaction, the accelerating effect of the acid content of the ionic liquid on the reaction becomes dominant. In the establishment of kinetic model, the activities of the ionic liquid catalysts synthesized in this paper are further analyzed and evaluated. This will provide basis and basic data support for the development of the technology of using ionic liquid to improve the transesterification reaction rate in industrial production.

\section{REFERENCES}

[1] Anjana S,Ram P,Renewable and Sustainable Energy Reviews,2000,4(2):111-133

[2] Demirbas A,Energy Conversion and Management,2003,44(13):2093-2109

[3] Zhao D B,Wu M,Kou Y,et al. Catal Today,2002,74:157 189

[4] You-Quan Deng, Beijing: China petrochemical press, 2006, 9-11.(in chinese)

[5] Jia-Hua Shi, Xun Sun, Chun-He Yang et al. Journal of chemistry, 2002,65 (4) : 243-250.(in chinese)

[6] Wu Q,Chen H,Han M H,et al,Chinese Journal of Ctalysis,2006,27(4):294-296

[7] Ti-Qian Jiang, chemical industry publishing press, 1984,87-155.(in chinese)

[8] Zhi-Yong Zhang,Zhu-Yin Yang, Beijing aerospace university press, 2006,123-168.(in chinese) 